\title{
FORMULATION OF AN ANTI-WRINKLE HYDROGEL FACE MASK CONTAINING ETHANOL EXTRACT OF NONI FRUIT (MORINDA CITRIFOLIA L) FOR USE AS A NUTRACOSMECEUTICAL PRODUCT
}

\author{
SILVIA SURINI*, ANNISA AULIYYA
}

Department of Pharmacy, Faculty of Pharmacy, Universitas Indonesia, Depok, Indonesia. Email: silvia@farmasi.ui.ac.id

Received: 21 April 2017, Revised and Accepted: 18 July 2017

\begin{abstract}
Objectives: Noni fruit (Morinda citrifolia L) containing ursolic acid and 3,3' bisdemethylpinoresinol can be useful as an anti-wrinkle agent. The hydrogel face mask is an alternative skin care product.

Methods: In this study, $0.1 \%$ ethanol extract of noni fruit was formulated with a concentration of $4 \%$ sodium alginate and $0.5 \%$ xanthan gum to form the hydrogel face mask. Physical stability of the hydrogel face mask was evaluated using organoleptic observation, consistency rates, swelling index measurements, and mechanical strength.
\end{abstract}

Results: The results showed that the hydrogel face mask has good water holding capacity, a tensile strength of $35.6524 \pm 0.8842 \mathrm{kgf} / \mathrm{cm}^{2}$, an elongation rate of $272.00 \pm 4.47 \%$, and remains stable in color and odor for 12 weeks.

Conclusions: This study revealed that the hydrogel face mask containing an ethanol extract of noni fruit is stable and has good physical characteristics; therefore, the hydrogel face mask is satisfactory for use as a nutracosmeceutical product.

Keywords: Hydrogel face mask, Morinda citrifolia, Noni fruit, Anti-wrinkle, Physical stability, Nutracosmeceutical.

(C) 2017 The Authors. Publishedby Innovare Academic Sciences Pvt Ltd. This is an open access article under the CCBY license (http://creativecommons. org/licenses/by/4. 0/) DOI: http://dx.doi.org/10.22159/ijap.2017.v9s1.41_47

\section{INTRODUCTION}

Cosmetic active molecules from various sources with complementary biological properties for effective management of wrinkles are popular in today's anti-aging skin care [1]. Nutracosmetics are an emerging class of health- and skin-care products that combine the benefits of nutracosmetical ingredients, as compared with synthetic cosmetic products, herbal products are mild, biodegradable, and have low toxicity profile [2]. Using herbal ingredients, different skin care products have proven to exhibit some beneficial properties, such as sunscreen, anti-aging, moisturizing, antioxidant, anti-cellulite, and antimicrobial effects [2,3]. Clinical trials in 2012 of a skin care regimen based on Morinda citrifolia $L$ resulted in significant reductions in lateral canthal fine lines and wrinkles and improved skin elasticity and firmness [4]. These benefits appeared within 2 weeks of product use. In addition, the product regimen was safe and non-irritating; therefore, a skin care regimen based on $M$. citrifolia L has a potential utility of improving skin health and appearance [4-6]. Ethanolic extract of noni fruit contains ursolic acid and 3,3'-bisdemethylpinoresinol, which could prevent wrinkles [7].

Ursolic acid inhibits human leukocyte elastase (HLE), and 3,3'-bisdemethylpinoresinol inhibits matrix metalloproteinases-1 (MMP-1) secretion. HLE cleaves the triple helix structure of Type I collagen, degrades the elastic fiber in human skin, and activates MMP-1. Thus, MMP-1 and HLE inhibitors may be useful in the prevention of photoaging and subsequent wrinkle formation [7].

The purpose of facial masks is to enhance skin care and provide beneficial effects to the skin. Hydrogels are often chosen as facial mask ingredients because of their high water content and their hydrophilic base which creates a matrix to the skin, thus allows high efficacy in delivering active ingredients into the skin [8]. Hydrogel masks not only have a superior moisturizing and regenerative effect on the skin [9] but are also able to control skin temperature and enhance physiological activity [10]. Furthermore, hydrogel masks have good elasticity and are convenient to apply [9].
In this study, the hydrogel mask was formulated with the ethanolic extract of noni fruit, sodium alginate, and xanthan gum. This formulation produces a hydrogel mask that has good physical stability and consistency. Physical stability was evaluated using organoleptic observation, consistency rates, swelling index measurements, and mechanical strength.

\section{MATERIALS AND METHODS}

\section{Materials}

Ethanolic extract of noni fruit (M. citrifolia L) (Balittro, Indonesia), sodium alginate (Sarda, Taiwan), xanthan gum (Cargill, China), propylene glycol (Dow Chemical Pacific, Singapore), glycerin (Ecogreen Oleochemicals, Singapore), sodium metabisulfite, methyl paraben (Clariant, Germany), propyl paraben (Clariant, Germany), and calcium chloride (Solvay Chemicals International, United States) was used.

\section{Preparation of noni fruit extract}

Noni fruit extract was extracted with $50 \%$ ethanol for three cycles and then evaporated with rotary vacuum evaporator until ethanolic extract was formed.

\section{Preparation of the hydrogel mask}

Hydrogel mask formulation described by composition and concentration is shown in Table 1 . Sodium alginate was dispersed into distilled water and homogenized for 10 minutes. Xanthan gum was then added to glycerin, and a mixture of xanthan gum-glycerin was added to the alginate gel to form the hydrogel base. Sodium metabisulfite was poured into $20 \mathrm{ml}$ of distilled water, and then, the ethanolic extract was added. The ethanolic extract mixture was then added to the hydrogel base and homogenized. Methyl paraben and propyl paraben were poured into propylene glycol then added to the hydrogel base and homogenized until a semisolid gel formed. The semisolid gel was then poured into a glass mold and dipped into a $2 \%$ calcium chloride mixture for 60 minutes. 


\section{Evaluation}

Hydrogel mask weight and size

Five pieces of the hydrogel mask were weighed on an analytical scale. Then, five sides of the mask (the center and four sides of the mask) were measured with a micrometer screw gauge. Measurements were repeated three times, and the mean values were used.

\section{Hydrogel mask acidity}

The hydrogel mask was dipped in $10 \mathrm{ml}$ of distilled water (acidity $6.5 \pm 0.1$ ) for $2 \mathrm{hrs}$ at room temperature. The hydrogel mask acidity was then measured with a $\mathrm{pH}$ meter. Measurements were repeated three times, and the mean values were used.

\section{Tensile strength and elongation rate}

The hydrogel mask form was cut into a piece measuring $1 \mathrm{~cm}^{2}$ then mounted on a texture analyzer (Com Ten Industries, United States). Tensile strength and elongation rate were determined using a crosshead speed of about $100 \mathrm{~mm} /$ minute. Measurements were repeated three times, and the mean values were used. The tensile strength and elongation rate were calculated from measured values using the following formula:

$$
\begin{aligned}
& \text { Tensilestrength }=\frac{\text { Force }(\mathrm{kgf})}{\text { Area }\left(\mathrm{cm}^{2}\right)} \\
& \text { Elongation rate }=\frac{\text { length difference }}{\text { initiallength }} \times 100 \%
\end{aligned}
$$

\section{Swelling index}

The hydrogel mask was cut into pieces measuring $1.2 \mathrm{~cm} \times 1.2 \mathrm{~cm} \times$ $0.04 \mathrm{~cm}$ [7]. The initial weight of the pieces was recorded, and then, they were dipped into $30 \mathrm{ml}$ of distilled water. The weight was measured in intervals of 1, 2, 3, 9, 12, 24, and $72 \mathrm{hrs}$ the first and second weeks. The swelling index of the hydrogel masks was calculated from measured values using the following formula:

Swelling Index $=\frac{\left(\mathrm{W}_{\mathrm{n}}-\mathrm{W}_{\mathrm{o}}\right)}{\mathrm{W}_{\mathrm{o}}} \times 100 \%$

- $\mathrm{W}_{\mathrm{n}}=$ hydrogel mask weight after hydration

- $\mathrm{W}_{\mathrm{o}}=$ hydrogel mask weight before hydration

\section{Consistency}

The hydrogel mask was placed in a penetrometer (Herzoo, Germany). The penetration value determined the consistency 5 seconds after the cone penetrated through the mask. Consistency rates were measured when the hydrogel mask was made and on week 12 of storage.

\section{Hydrogel mask shrinkage}

The hydrogel mask was cut into rectangular pieces each with an area of about $36 \mathrm{~cm}^{2}$. Areas and weight were measured every 10 minutes for $2 \mathrm{hrs}$ from the beginning of the experiments. The times when there was area shrinkage were recorded.

\section{RESULTS AND DISCUSSIONS}

In this study, $0.1 \%$ ethanol extract of noni fruit was formulated with a concentration of $4 \%$ sodium alginate, $0.5 \%$ xanthan gum, $5 \%$ glycerin, and $2.5 \%$ propylene glycol, which produced a hydrogel mask with good consistency and elasticity.

\section{Hydrogel mask weight and thickness}

The hydrogel mask weight before being dipped in $2 \%$ calcium chloride solution was $70 \mathrm{~g}$. After being dipped, there was shrinkage of $52.8333 \pm 4.7226 \mathrm{~g}$, and the hydrogel mask thickness measured $0.076 \pm 0.002 \mathrm{~mm}$. In general, the preferred thickness of the hydrogel mask is from 0.5 to $1.5 \mathrm{~mm}$, regardless of the presence or absence of a support, to maintain shape and handle ability [10].

\section{Hydrogel mask acidity}

The hydrogel mask acidity value was $5.57 \pm 0.14$ and decreased over 12 weeks of storage to $4.57 \pm 0.11$. The acidity value of the skin was appropriate ( $\mathrm{pH}$ between 4.5 and 6.5); therefore, the hydrogel mask was convenient to be used as a skin care product (Fig. 1).

\section{Tensile strength and elongation rate}

Minimum mechanical strength for the hydrogel mask is more than $0.1 \mathrm{kgf} / \mathrm{cm}^{2}$. The tensile strength test result is $35.6524 \pm 0.8842 \mathrm{kgf} / \mathrm{cm}^{2}$, thus the hydrogel mask has good mechanical strength. The results of the elongation rate measurements are $272.00 \pm 4.47 \%$ demonstrating that the hydrogel mask has good elongation and elasticity.

\section{Swelling index}

The weight of the pieces increased within the second week, with a swelling index value of $113.32 \%$ (Fig. 2). The weight of the pieces

Table 1: Hydrogel mask formulation

\begin{tabular}{ll}
\hline Composition & Concentration (g) \\
\hline Noni extract & 0.10 \\
Sodium alginate & 4.00 \\
Xanthan gum & 0.50 \\
Propylene glycol & 2.50 \\
Glycerin & 5.00 \\
Sodium metabisulfite & 0.02 \\
Methyl paraben & 0.20 \\
Propyl paraben & 0.10 \\
Fruit essence & 0.10 \\
Distilled water & Ad 100 \\
\hline
\end{tabular}

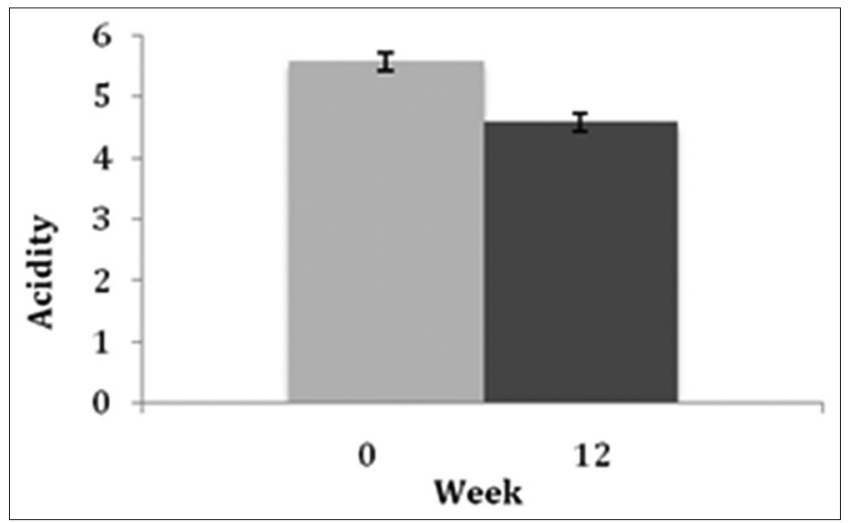

Fig. 1: Acidity value of the hydrogel mask immediately after formation and on week 12 of storage chart

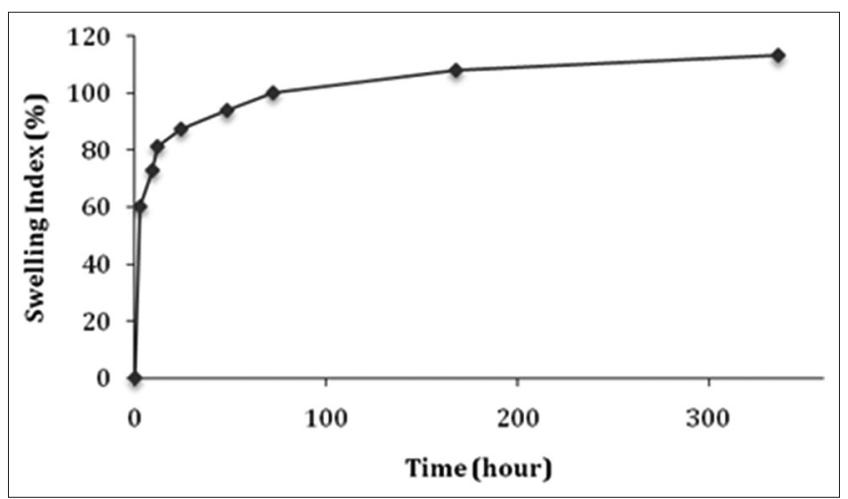

Fig. 2: Hydrogel mask swelling index in distilled water during 2-week measurement (hour 0 until hour 336) 


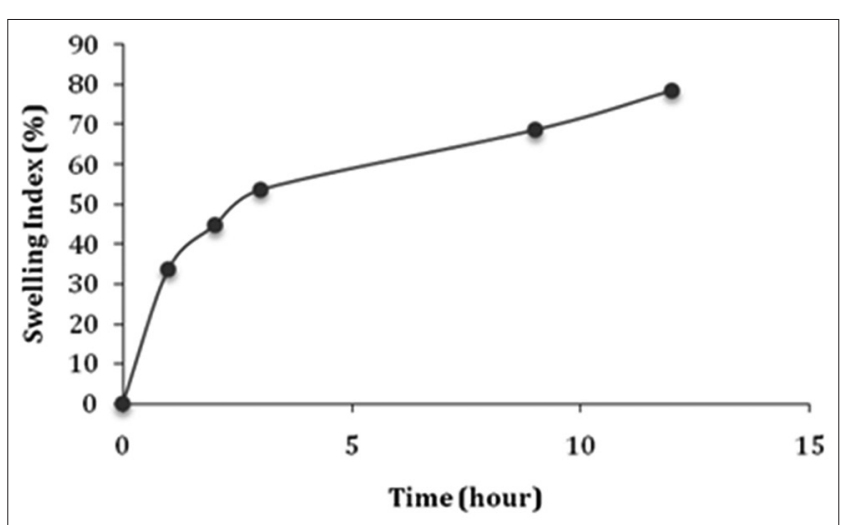

Fig. 3: Hydrogel mask swelling index in distilled water during 2-week measurement (hour o to hour 12)

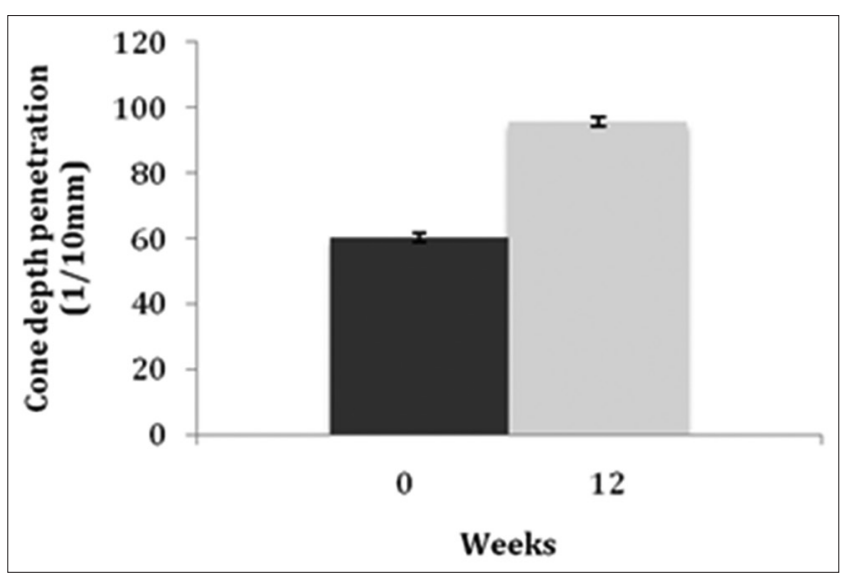

Fig. 4: Consistency of hydrogel mask when formed and on week 12 of storage

increased rapidly for the first $3 \mathrm{hrs}$, with a swelling index value of $33.79 \%$, the first hour, and a swelling index value of $44.78 \%$, the second hour (Fig. 3). The weight of the pieces increased constantly, showing that a hydrogen bond had developed and enabling the structure to swell. The hydrogel mask has good water holding capacity.

\section{Consistency}

The consistency rate was measured with a penetrometer with a cone mass of $263.6 \mathrm{~g}$. The consistency rate of the hydrogel mask was $6.03 \pm 1.53 \mathrm{~mm}$, measured when the hydrogel mask was formed.
Then, on week 12 of storage, the consistency rate was $9.57 \pm 0.58 \mathrm{~mm}$., showing that the consistency of the hydrogel mask decreased during the 12-week storage in propylene glycol (Fig. 4).

\section{Hydrogel mask shrinkage}

The hydrogel mask was cut into rectangular pieces, each with an area of about $36 \mathrm{~cm}^{2}$. The initial mass used was $5.3871 \pm 0.1733 \mathrm{~g}$. Shrinkage was first observed after about 60 minutes and was measured at $35.40 \pm 0.00 \mathrm{~cm}^{2}$. It means that a condition of the hydrogel mask had not changed for about $1 \mathrm{hr}$ after the hydrogel mask was used [9]. The hydrogel mask shrinkage after $8 \mathrm{hrs}$ was $26.44 \pm 0.30 \mathrm{~cm}^{2}$, and the hydrogel mask mass continuously decreased over 8 hrs, having a final weight of $2.3562 \pm 0.0769 \mathrm{~g}$. The shrinkage was caused by water evaporation, indicating that the hydrogel mask should be stored in a sealed container.

\section{CONCLUSION}

This study revealed that the hydrogel face mask containing an ethanol extract of noni fruit is stable and has good physical characteristics; therefore, the hydrogel face mask is satisfactory for use as a nutracosmeceutical product.

\section{REFERENCES}

1. Arsiwala S, Tahiliani S, Jerajani H, Chandrashekhar BS, Aurangabadkar S, Kohli M, et al. Evaluation of topical anti-wrinkle and firming (AWF) for women, anti-wrinkle and firming (AWF) for men and deep wrinkles for wrinkles on face and neck. Asian J Pharm Clin Res 2013;6(3):86-9.

2. Chanchal D, Swarnlata S. Novel approaches in herbal cosmetics. J Cosmet Dermatol 2008;7:89-95.

3. Anitha T. Medicinal plants used in skin protection. Asian J Pharm Clin Res 2012;5(3):35-8.

4. West BJ, Sabin RA. Efficacy of a Morinda citrifolia based skin care regimen. Curr Res J Biol Sci 2012;4(3):310-4.

5. Ali M, Kenganora M, Manjula SN. Health benefits of Morinda citrifolia (Noni): A review. Pharmacogn J 2016;8(4):321-34

6. Assi RA, Darwis Y, Abdulbaqi IM, Khan AA, Vuanghao L, Laghari MH. Morinda citrifolia (Noni): A comprehensive review on its industrial uses, pharmacological activities, and clinical trials. Arab J Chem 2015;10(5):691-707.

7. Matsuda H, Masuda M, Murata K, Abe Y, Uwaya A. Study of the antiphotoaging effect of noni (Morinda citrifolia). In: Duc DH, editor. Melanoma - From Early Detection to Treatment. Rijeka, Croatia: InTech; 2013.

8. Quattrone A, Czajka A, Sibilla S. Thermosensitive hydrogel mask significantly improves skin moisture and skin tone; Bilateral clinical trial. Cosmetics 2017;4(17):1-18.

9. Lim KB, Hur W, Kim JY, Lee DH. Patent No. US 2010/0112058 A1. United States; 2010

10. Tsujihata S. Patent No. US 2010/0239621 A1. United States; 2010. 